\title{
EL SIGNIFICADO DE UN VÍNCULO TEXTUAL INESPERADO: RAYUELA "TUÉRCELE EL CUELLO AL CISNE"
}

CATHY L. JRADE

Indiana University

En el último capítulo de la primera parte de Rayuela, Horacio Oliveira pasea por las calles reflexionando sobre sus experiencias en París y sobre su búsqueda, que ha dominado en su vida y en las páginas anteriores de la novela. Está a punto de conceder que su búsqueda del "kibbutz del deseo" ha sido un fracaso, ya que se ha dado cuenta de que el kibbutz es una ciudadela sólo alcanzable con armas fabulosas, no con el alma de Occidente, ni con el espíritu. Mientras hace estas reflexiones, Horacio entra en el mundo de los clochards y se abandona a un comportamiento que va en contra de lo esperado. En ese momento se acuerda de un previo llamado para romper las normas establecidas: ... Oliveira se estaba acordando de que también Heráclito había dicho que si no se esperaba jamás se encontraría lo inesperado, tuércele el cuello al cisne, había dicho Heráclito, pero no, por supuesto no había dicho semejante cosa, ... a Oliveira le subía como un eructo vinoso el doble apellido del cisne estrangulable, y le daban unas enormes ganas de reírse y contarle a Emmanuèle,... Oliveira... seguía pensando en que sólo el que espera podrá encontrar lo inesperado... Evidentemente había que torcerle el cuello al cisne, aunque no lo hubiese mandado Heráclito". Para entender satisfactoriamente lo que implica la aceptación por parte de Horacio del mandato destructivo de González Martínez hace falta una comprensión del mandato mismo, del movimiento literario en que se generó, tanto como un entendimiento de lo que el protagonista de Cortázar percibe ser la meta que comparte con el poeta posmodernista. Para llegar a esta comprensión, hay que volver al modernismo.

El modernismo hispanoamericano, en contraste con la explicación ofrecida por algunas teorías anteriores, no se formó en relativo aislamiento como una

\footnotetext{
1 Julio Cortázar, Rayuela (Buenos Aires: Editorial Sudamericana, 1968), p. 247. Todas las citas son de esta edición y las páginas se darán entre paréntesis.
} 
reacción contra y una negación de la literatura precedente. ${ }^{2}$ La metafísica romántica de la integración y la implacable búsqueda romántica de la inocencia, que llegaron a los escritores hispanoamericanos principalmente a través de Francia, dieron forma al carácter fundamental del movimiento. EI énfasis crítico sobre la calidad refinada y primorosa del verso modernista, casi hasta la exclusión de otros aspectos artísticos, ha desviado aún más la atención de los orígenes verdaderos del movimiento y de su seria subestructura filosófica. Además, esta lectura desequilibrada inadvertidamente ha puesto en cuestión la vigencia de los modernistas. ${ }^{3}$ A causa de una persistente desconfianza de la "artificialidad"en el arte y su asociación con la afectación, la insinceridad, la superficialidad, y una falta de interés en las realidades básicas de la vida, el enfoque crítico en las formas artificiosas del modernismo ha causado que el movimiento parezca anticuado. Esta actitud es errónea y obstruye la percepción de los vestigios del arte modernista que continúan funcionando en la literatura hispánica contemporánea.

Las características del arte modernista tienen su base en una cosmología formulada bajo la influencia de las creencias esotéricas populares en Europa durante el siglo XIX. ${ }^{4}$ Las manifestaciones formales del arte modernista no definen el movimiento, sino que reflejan una lucha profunda para enfrentar el significado de la existencia y las perplejidades de la responsibilidad poética. Aunque Darío, líder y centro intelectual del movimiento, y otros modernistas buscaban respuestas en una variedad de religiones, sectas, e ideologías, adoptando una visión flexible y sincrética del mundo, en general, encontraron, como los románticos y los simbolistas antes, una idea unificadora y una piedra clave filosófica en los conceptos de la unidad y la armonía. Esperaban redimir al hombre, a quien veían como fragmentado-fuera de contacto consigo mismo, con sus semejantes, y con la naturaleza-, promoviendo una reconciliación con un universo ordenado y benevolente.

\footnotetext{
2 Véase, por ejemplo, Federico de Onís, Antología de la poesía española e hispanoamericana, 1882-1932 (Madrid: Imprenta de la Libreria y Casa editorial Hernando, S.A., 1934), p. xiii.

3 Véase Edgardo Buitrago, "Consideraciones polémicas acerca de la vigencia y actualidad de Rubén Darío", Estudios sobre Rubén Dario, ed. de Ernesto Mejía Sánchez (México: Fondo de Cultura Económica, 1968), pp. 596-625.

${ }^{4}$ Véase, por ejemplo, M. H. Abrams, Natural Supernaturalism: Tradition and Revolution in Romantic Literature (New York: W. W. Norton and Co., Inc., 1973); Gwendolyn Bays, The Orphic Vision: Seer Poets from Novalis to Rimbaud (Lincoln, Nebraska: University of Nebraska Press, 1964); John Senior, The Way Down and Out: The Occult in Symbolist Literature (Ithaca, N.Y.: Cornell University Press, 1959); Octavio Paz, Los hijos del limo. Del romanticismo a la vanguardia (Barcelona: Editorial Seix Barral, S.A., 1974); y mi estudio de próxima aparición Modernism and the Romantic Search for Unity: Ruben Dario and Esoteric Tradition.
} 
Además, esta esperanza de reconciliación dominante entre los modernistas se extendia hasta incluir la doctrina y el simbolismo religioso. Fue el carácter sincrético fundamental de las sectas ocultistas que les preporcionaron los medios de lograr una visión armoniosa y unificada del mundo. $Y$, puesto que la creencia esotérica en la unidad de todas las religiones se extendía al simbolismo de aquellas religiones, la indole sincrética del ocultismo les permitió a los modernistas aprovechar conceptos y símbolos de doctrinas diferentes como si fuesen rayos de una rueda que, al converger en su eje, diese a su obra una unidad poética integradora de épocas y creencias diversas. Un desarrollo significativo apoya esta nueva manera de concebir el papel poético de las creencias y los símbolos. Los símbolos específicos y su original contexto religioso han llegado a ser menos importantes que su nuevo papel en su nueva estructura poética que intenta captar la esencia del universo armonioso. Así, el poeta implícita mente niega la autoridad absoluta de todo sistema doctrinal. Por consiguiente, el recurrir al ocultismo o al catolicismo no representa necesariamente una vacilación de creencias personales. El recurrir a un código simbólico en vez de a otro reafirma la completa libertad del artista para tratar de ajustar las palabras a "la iniciación melódica".5 Al mismo tiempo, sin embargo, el poeta tiene que reconocer el carácter tentativo del discurso poético, con el cual, por medio de la magia del lenguaje, espera captar la verdad.

Esta concepción del lenguaje y del mundo no se limita a los modernistas. Estudios recientes han empezado a indicar la importancia fundamental de estas características a muchos escritores del siglo XX. En su introducción a Waiting for Pegasus: Studies of the Presence of Symbolism and Decadence in Hispanic Letters, Grass and Risley sostienen que el fenómeno artístico al cual pertenece el modernismo es a la vez internacional y duradero-vigente por lo menos hasta la aparición de la vanguardia. ${ }^{6} \mathrm{La}$ mayor parte de los rasgos modernistas duran, sin duda alguna, a través de la época posmodernista, durante la cual, por ejemplo, el clásico soneto posmodernista de González Martínez, "Tuércele el cuello al cisne" (1911), refleja las dominantes preocupaciones modernistas por los aspectos "ocultos" del lenguaje y de la realidad.

González Martínez no critica al cisne modernista de Darío, cuya elegancia natural encarna el ritmo del universo, sino que reacciona ante las imitaciones

\footnotetext{
5 Rubén Dario, "Yo persigo una forma...", Poesias completas, ed. de Alfonso Méndez Plancarte, aumentada por Antonio Oliver Belmás, $11^{\text {a }}$ ed. (Madrid: Aguilar, S.A., 1968), p. 622.

6 Roland Grass and William R. Risley, ed. de, Waiting for Pegasus: Studies of the Presence of Symbolism and Decadence in Hispanic Letters (Macomb: Western Illinois University, 1979), pp. 11-12.
} 
superficiales del verso modernista, las cuales sustituían "engañoso plumaje" por el contacto con "el alma de las cosas" y "la voz del paisaje". El rechazo posmodernista de estas formas que llegaban a ser resonancias huecas de la versificación modernista y, por consiguiente, obstáculos que estorbaban la visión de la armonía sólo se puede entender como una continuación del deseo modernista de crear un lenguaje vivo que encierre el ritmo de la existencia. La esmerada elección de González Martínez de su nuevo emblema destaca esta continuidad con el modernismo. Como señala el poeta mexicano, el búho no tiene la donosura del cisne, pero su vista puede penetrar la oscuridad. La obvia atención a la belleza formal se reemplaza, de esta suerte, por un énfasis en la claridad de percepción. La fe subyacente que se vislumbra en este cambio es que, si el orden del universo se percibe, la belleza surgirá, o, en otras palabras, que el orden del universo coincide perfectamente con los valores estéticos.

Estas suposiciones poéticas, que tienen sus raíces en la doble tradición romántico-esotérica que vino a Hispanoamérica desde Europa, aparecen detallada y coherentemente desarrolladas en la literatura española en la obra de Valle Inclán, especialmente en La lámpara maravillosa, tratado publicado en 1916, cinco años después de "Tuércele el cuello al cisne". Sólo unos pocos años más tarde, en la poesía de la Generación del 27, resurge la búsqueda modernista de un nuevo lenguaje a través del cual el hombre puede lograr la comunión con la naturaleza. La importancia dada a las imágenes y a la innovación estructural surrealistas refleja un reconocimiento de la insuficiencia de los patrones de expresión existentes. Además, el optimismo de las obras más tempranas de la Generación del 27 seguramente está vinculado con la fe romántica en un universo ordenado y descifrable, cuyos secretos pueden ser descubiertos dentro y a través de la poesía. El modernismo, por lo tanto, no termina ni con el posmodernismo ni con la Generación del 27 sino con la vanguardia, en la cual la búsqueda de la armonía y la unidad se convierte en una investigación de la pérdida de ellas. Esta postulación de un sentido de pérdida se manifiesta en la poesía con protestas contra las previas tradiciones literarias, con un énfasis autoconsciente en los aspectos juguetones y superficiales del arte, y con intentos deliberados de poner en ridículo como vacuas y entorpecedoras las sensibilidades burguesas. Pero cuando la furia y la indignación de los primeros vanguardistas se apaciguaron, los autores volvieron de nuevo a la tradición ocultista para encontrar modos alternativos de concebir el papel del hombre, del lenguaje y del orden (o del desorden) del universo. Este recurso al ocultismo es importante en las obras de Cortázar, Carpentier y Borges, por mencionar solamente a algunos de los más importantes, y también destaca la centralidad del modernismo en un aspecto de la literatura contemporánea que a menudo se pasa por alto en el movimiento anterior, es decir, un sentido de ruptura. 
El intento modernista de romper la dominación de la lógica y de la coherencia conceptual anticipa la desconfianza del lenguaje que es clave en el arte del siglo XX. A medida que se desarrollaba el modernismo, el signo poético se volvía cada vez más hermético, ilógico, anómalo, y alejado del discurso natural, y los poetas modernistas empeza ban a transgredir los límites de la percepción normal, con la esperanza de reestablecer las virtualidades semánticas. ${ }^{7}$ Carlos Fuentes, en la conclusión de su La nueva novela hispanoamericana hace hincapié en este aspecto lingüístico de la reacción hispanoamericana ante el positivismo, subrayando su naturaleza crucial para el desarrollo de la nueva novela. La tradición positivista "concede a la palabra una función amable colindante con la bufonería: el escritor puede divertir, incluso advertir... pero no puede, llanamente y sin prefijos, verter. Pero sólo la palabra vertida puede descolorar eso que pasa por 'realidad' para mostrarnos la real: lo que la 'realidad' consagrada oculta: la totalidad escondida o mutilada por la lógica convencional (por decir: de conveniencia)". ${ }^{8}$ Pero de este punto de partida común arrancan dos caminos divergentes. Yurkievich, en su perceptivo análisis del carácter doble del absurdo, traza estas dos rutas seguidas por los autores hispanoamericanos. El absurdo positivo libera al poeta de la causalidad empírica y le permite, por vía de la imaginación sin ataduras, inventar mundos inéditos (creacionismo de Huidobro) o retornar por el mito a las fuentes originales. El absurdo negativo enajena la razón y revela la insignificancia del existir, la opacidad del mundo, la alteridad infranqueable de las cosas (Trilce, Residencia en la tierra, Altazor). ${ }^{9}$ En la imaginación modernista-especialmente la de Darío-lo que se queda encerrado detrás de los muros de las categorías habituales coincide con las imágenes antiguas de la paz y de la tranquilidad. Según el escritor contemporáneo, la realidad oculta generalmente no corresponde a ningún conjunto de concepciones preestablecidas; al contrario, a menudo se concibe la verdad fundamental de la vida y de la literatura como una inversión de las imágenes tradicionales. La resultante aparición de lo inesperado es particularmente notable en las novelas y en los cuentos de Julio Cortázar. ${ }^{10}$

En el capítulo 99 de Rayuela, Cortázar resume su punto de vista en la discusión entre Horacio, Etienne, Gregorovius, Perico y Babs sobre la

\footnotetext{
7 Saúl Yurkievich desarrolla esta conclusión en el segund o capítulo de su libro Celebración del modernismo (Barcelona: Tusquets Editor, 1976), pp. 11-23.

${ }^{8}$ Fuentes, La nueva novela hispanoamericana (México, Joaquín Mortiz, 1974), p. 85.

${ }^{9}$ Yurkievich, p. 17.

10 Véa se Sara Castro-Klarén, "Ontological Fabulation: Toward Cortázar's Theory of Literature", The Final Island: The Fiction of Julio Cortázar, ed. de Jaime Alazraki e Ivar Ivask (Norman: University of Oklahoma Press, 1976), pp. 140-150.
} 
insuficiencia del lenguaje y la necesidad de romper sus límites. Horacio comenta sobre las teorías de Morelli: "Lo único claro en todo lo que ha escrito el viejo [Morelli] es que si seguimos utilizando el lenguaje en su clave corriente, con sus finalidades corrientes, nos moriremos sin haber sabido el verdadero nombre del día. Es casi tonto repetir que nos venden la vida, como decía Malcolm Lowry, que nos la dan prefabricada. También Morelli es casi tonto al insistir en eso, pero Etienne acierta en el clavo: por la práctica el viejo se muestra y nos muestra la salida. ¿Para qué sirve un escritor si no para destruir la literatura?"(p. 503) Horacio continúa su ataque contra la literatura al contestar la pregunta de Babs sobre las implicaciones de este enfoque. Horacio rechaza como inadecuado el previo concepto del lenguaje que formaba la base de la poética romántica, simbolista, y modernista. "Hasta hace unos veinte años había la gran respuesta: la Poesía, ñata, la Poesía. Te tapaban la boca con la gran palabra. Visión poética del mundo, conquista de la realidad poética. Pero después de la última guerra, te habrás dado cuenta de que se acabó" (p. 504).

Por lo tanto, el rechazo del lenguaje no es simplemente el de la reseca intelectualización del positivismo y su perspectiva limitada; el ataque se opone a todas las visiones inmutables de la realidad. Más tarde en la misma discusión, Horacio aclara que su crítica es extensa. "La idea es que la realidad, aceptes la de la Santa Sede, la de René Char o la de Oppenheimer, es siempre una realidad convencional, incompleta y parcelada"(p. 507). De acuerdo con esta evaluación, Etienne comenta: "... esa verdadera realidad, repito, no es algo por venir, una meta, el último peldaño, el final de una evolución. No, es algo que ya está aquí, en nosotros. Se la siente, basta tener el valor de estirar la mano en la oscuridad" (p. 508). El problema que destaca el comentario de Etienne y que examina Cortázar a lo largo de Rayuela es que el hombre frecuentemente no tiene el valor de meter la mano en la oscuridad. Cortázar expone la posibilidad de que el hombre moderno no solamente es incapaz de penetrar la realidad, sino que evita adrede contacto con la realidad mediante los hábitos y la rutina cotidianos-entre los cuales el más obvio es el lingüístico."

Esta desgana por parte del hombre moderno de meter la mano en la oscuridad se basa en su miedo de que la realidad, la que existe detrás de las

\footnotetext{
1 El segund o epígrafe de la novela, de Lo que me gustaría ser a mi si no fuera lo que soy de César Bruto, se refiere a este entregarse al hábito. La última frase del pasaje citado subraya el papel de la responsabilidad individual. "¡Y ojalá que lo que estoy escribiendo le sirbalguno para que mire bien su comportamiento y que no searrepienta cuando es tarde y ya todo se haiga ido al corno por culpa suya!"(n.p.).
} 
apariencias y detrás de los patrones establecidos, puede ser tan ajena y extraña que parezca horrible y terrorífica. ${ }^{12}$ La posibilidad sugerida por el fin de la narración, es decir, que la única manera de que Horacio pueda alcanzar el cielo es caerse de cabeza en la rayuela, refuerza esta visión espantosa del "yonder". También, la posibilidad señalada por Etienne y apoyada por Horacio que "A lo mejor en el mismísimo centro hay un perfecto hueco" ofrece muy poco consuelo (p. 198). Aun Horacio, quien se ve a sí mismo como indagador, reconoce su propia ambivalencia cuando se trata de hundirse en los "ríos metafísicos" de la existencia. ${ }^{13}$ Esta irresolución de ir "más allá" le es especialmente evidente cuando se compara a sí mismo con La Maga: “. . p pero una vez más yo volví a sentar el falso orden que disimula el caos, a fingir que me entregaba a una vida profunda de la que sólo tocaba el agua terrible con la punta del pie. Hay ríos metafísicos, ella los nada como esa golondrina está nadando en el aire, girando alucinada en torno al campanario, dejánd ose caer para levantarse mejor con el impulso. Yo describo y defino y deseo esos ríos, ella los nada" (p. 116).

Así en Rayuela, como en el verso modernista, el problema del lenguaje se vincula con la suposición de una realidad oculta. Y, también como en el verso modernista, Rayuela une muchas de las formas de la búsqueda humana del más allá: el budismo, el kabalismo, la filosofía china, el zoroastrismo, el orfismo, la teosofía, el jazz, el arte, etc. En su artículo reciente, Gareth Davies examina la influencia de los fundamentos teosóficos del arte abstracto tal como lo formuló Mondrian. ${ }^{14}$ En este recurrir al ocultismo para discutir cuestiones del lenguaje y de la realidad, Cortázar demuestra su afinidad latente con el modernismo. Nunca está más claro este nexo que en el capítulo 36 con las tres referencias al soneto de González Martínez, "Tuércele el cuello al cisne". Mientras que el violento mandato iconoclasta que da el título del poema acentúa la afirmación de la ruptura y de la transgresión por parte de Cortázar, el resto del poema funciona en la novela como un autoreflexivo y silencioso comentario sobre la búsqueda de Horacio. ${ }^{15}$

\footnotetext{
12 "Behind" o "beyond" es la metáfora utilizada por Cortázar, quien, aun en español, indica una preferencia por las palabras inglesas, inclusive por la palabra "yonder" (p. 506).

13 "Ya para entonces me había dado cuenta de que buscar era mi signo, emblema de los que salen de noche sin propósito fijo, razón de los matadores de brújulas" (p. 20).

14 Gareth A. Davies, "Mondrian, Abstract Art, and Theosophy in Julio Cortázar's Rayuela", Proceedings of the Leeds Philosophical and Literary Society, 16, Part VI (Leeds: Leeds Philosophical Society, 1976), pp. 127-247.

15 Véase la referencia al poema hecha por Margery A. Safir en "An Erotics of Liberation: Notes on Transgressive Behavior in Hopscotch and Libro de Manuel", en Final Island, pp. 84-96.
} 
Como se ha indicado anteriormente, el cisne "estrangulable" es de "engañoso plumaje". La ofensa del ave es la decepción o, más específicamente, su disposición a usar los refinamientos atractivos y superficiales de la vida para ocultar las realidades más profundas y, quizás, más oscuras de la existencia. Su cuello se debe torcer no solamente porque el ave representa patrones establecidos de conducta y expresión, sino porque "no siente el alma de las cosas ni la voz del paisaje". Aunque finge ser el cisne modernista, no lo es. Es una copia falsa y accesible que no consigue encarnar el orden del universo. Del mismo modo, Horacio-por lo menos el Horacio de la primera parte - aparenta querer ponerse en contacto con la vida, pero muy frecuentemente no consigue salir de detrás de los patrones fijos del comportamiento y del lenguaje. ${ }^{16}$ Sus intentos de romper estos moldes muchas veces se convierten en insultos violentos a las sensibilidades burguesas. Un ejemplo de estos esfuerzos es su conducta con la clocharde del capítulo 36, en que se cita el soneto. Este comportamiento por parte de Horacio representa su deseo de seguir la orden del poema de González Martínez. Pero la relación del soneto con Rayuela no termina con el título.

El consejo del segundo cuarteto es especialmente pertinente a Horacio en el momento en que él evoca el soneto, porque Horacio ha obstruido-adrede o sin querer-, con ideas, libros, y papeles apropiados, toda percepción directa de la vida. A pesar de su erudición, él no es el poeta/vidente que es La Maga, y ella se lo dice en el capítulo 3. "Partís del principio [de que la reflexión debe preceder a la acción] dijo La Maga-, Qué complicado. Vos sos como un testigo. . . Vos creés que estás en esta pieza pero no estás. Vos estás mirando la pieza, no estás en la pieza"(p. 34). Aun más tarde, en la Argentina, Traveler le critica a Horacio por su manera de buscar. Le dice a Horacio, "Buscás eso que llamás la armonía, pero la buscás justo ahí donde acabás de decir que no está..."(p. 327). En contraste, es La Maga, quien sigue el mandato del soneto de adorar intensamente la vida y quien, como está sugerido en el segundo cuarteto, percibe que la vida comprende su homenaje. Es ella, en las palabras de Horacio, la que se asoma a cada rato a esos grandes ámbitos sin tiempo que los demás buscaban dialécticamente (p. 41).

Pero el soneto no sólo elucida los fracasos de Horacio. Al contrario, los últimos seis versos parecen indicar que Horacio, como el búho, aspira a dejar el regazo de Minerva para empezar a interpretar el misterioso libro del silencio nocturno. El talento particular del búho no es su intelecto sino su vista.

\footnotetext{
16 Por ejemplo, se acuerda en el primer capítulo que el día que conoció a La Maga ..."todo anduvo mal, porque mis costumbres argentinas me prohibían cruzar continuamente de una vereda a otra para mirar las cosas más insignificantes en las vitrinas a penas iluminadas de unas calles que ya no recuerdo" (p. 18).
} 
Dejando la comodidad de la protección de Palas, Horacio procede a penetrar el lado oscuro del hombre y los misterios de la existencia. El último terceto recalca su rechazo de los caminos tradicionales hacia la percepción. Escoge, en cambio, seguir el ejemplo ofrecido por La Maga, cuya hora es la noche. ${ }^{17}$ Sus momentos de mayor percepción ocurren durante sus descensos nocturnos al mundo diabólico de los clochards y al sótano infernal del manicomio. ${ }^{18}$

El descenso al sótano del manicomio representa una entrada en la infraestructura de la cordura humana, que limita y ordena el movimiento fluido y desarreglado de los aspectos oscuros de la existencia. También representa una entrada en la faceta de la vida que es a la vez magia y terror-precisamente el aspecto de la vida personificado por Johnny Carter en "El perseguidor". En Rayuela, Cortázar señala primero la magia. "De alguna manera habían ingresado en otra cosa, en ese algo donde se podía estar de gris y ser de rosa, donde se podía haber muerto ahogado en un río... y asomar en una noche de Buenos Aires para repetir en la rayuela la imagen misma de lo que acababan de alcanzar, la última casilla, el centro del mandala, el Ygdrassil vertiginoso por donde se salía a una playa abierta, y a una extensión sin límites, al mundo debajo de los párpados que los ojos vueltos hacia adentro reconocían y acataban" (p. 374). Pero una vez que se vislumbra el envés de la realidad, la rutina se desmenuza y los patrones establecidos se hacen pedazos. El capítulo 56 documenta la difícil tensión entre la magia y el terror, y destaca-igual que hace el destino de Robert Michel en "Las babas del diablo"-la impotencia esencial del hombre frente a estas fuerzas desenfrenadas. Cortázar parece sugerir que la disolución de las estructuras habituales revela un mundo en que el hombre, tal como se le conoce en la cultura occidental, no puede sobrevivir. Sólo en casos de éxito falso o de penetración incompleta-tal como el caso de Bruno en "El perseguidor"- - puede uno seguir adelante.

Esta concepción de lo que se queda oculto detrás de la rutina y detrás de los patrones habituales es antitética a la sostenida de Darío y de otros modernistas, quienes suponían que la poesía-específicamente el carácter musical de la poesía--podría descubrir el orden y la belleza del universo, los cuales habían sido encubiertos por estructuras conceptuales. La doble tradición romántico-esotérica ofrecía una base sobre que se podía apoyar una fe en la descifrabilidad del universo o, en otras palabras, una fe en que el universo consiste de símbolos que guardan relación con el origen. Estos

\footnotetext{
${ }^{17}$ Madame Léonie capta la esencia de la Maga con la siguiente descripción: "Ella sufre en alguna parte. Siempre ha sufrid o. Es muy a legre, ad ora el a marillo, su pájaro es el mirlo, su hora la noche, su puente el Pont des Arts" (p. 18).

18 Véase Safir, p. 85.
} 
símbolos simplemente deben ser descubiertos y "traducidos" al lenguaje humano. La consecuente aspiración romántica, simbolista y modernista por liberar los signos del pensamiento congelado por vía de la elección libre de la palabra o del símbolo "justo de entre una variedad de sistemas simbólicos, exponía la independencia intrínseca de los signos. De esta suerte, se hizo posible concebir los signos como entidades totalmente divorciadas de su significación original. Mediante el inesperado vínculo textual entre Rayuela y "Tuércele el cuello al cisne", Cortázar dirige nuestra atención a esta transición de la lucha modernista por liberar el lenguaje de sus limitaciones positivistas a la aceptación moderna de la realidad desconocida y horrorosa que el lenguaje esconde. 